\title{
Comparison of Photoselective Vaporization of Prostate (KTP-PVP) Vs. Transurethral Resection of Prostate (TURP): A Prospective, Randomized Study
}

\author{
Harsh Gupta, Suresh Goyal \\ Dr S N Medical College, Jodhpur, Rajasthan, India
}

\begin{abstract}
Objectives: To evaluate the efficacy and safety of photoselective vaporization of prostate (PVP) using a $100 \mathrm{~W}$ potassium titanyl phosphate (KTP) laser in comparison to transurethral resection of prostate (TURP) in patients of benign prostatic enlargement (BPE). Materials and Methods: Between Jan 2014 and December 2015, 121 patients satisfying the eligibility criteria underwent surgery 62 PVP (Group A); 59 TURP (Group B). The groups were compared for functional outcome, perioperative parameters and complications, with a follow up of Gmonths. P value $<0.05$ was considered statistically significant. Results: The baseline characteristics of the two groups were comparable. Mean age was 65.72 years and 64.38 years, mean IPSS score was 19.02 and 20.18 , mean prostate volume was $43.67 \mathrm{cc}$ and $48.78 \mathrm{cc}$ in Group $A$ and B, respectively. Improvements in IPSS, QOL, prostate volume, Q max and PVRU at 6 months were similar in both groups. PVP patients had longer operating time, lesser perioperative blood loss, shorter catheterization time when compared to TURP. Conclusions: In patients of benign prostatic enlargement, KTP-PVP is a good alternative to TURP with durable results at 6 months follow up with additional benefits of lesser perioperative blood loss, lesser transfusion requirements and a shorter catheterization time.
\end{abstract}

Keywords: Benign prostatic hyperplasia, photoselective vaporization, transurethral resection of prostate, potassium titanyl phosphate laser

\section{Introduction}

Transurethral resection of the prostate (TURP) is still viewed as the "Gold standard" for benign prostatic enlargement (BPE).TURP is a technically demanding procedure requiring substantial practice to master it. The learning curve for TURP, as most urologists would agree, ranges from 50-75 cases. This has driven the search for a safer, easier to perform alternative that is as efficacious as TURP for the surgical management of BPE. Among the emerging surgical therapies for BPE, laser is the most promising. Potassium titanyl phosphate (KTP) laser, also known as "Green Light" laser is one such laser with a wavelength of $532 \mathrm{~nm}$. It is selectively absorbed by hemoglobin within prostatic tissue, thus permitting photoselective vaporization of prostate (PVP). PVP is considered to be easier to learn and perform than TURP and competence occurs following 10-20 procedures.[1] We performed a prospective, randomized study to examine the efficacy and safety profile of KTP-PVP when compared to TURP.

\section{Material and Methods}

Between January 2014 and December 2015, consecutive patients attending the Urology OPD with lower urinary tract symptoms (LUTS) secondary to benign prostatic enlargement (BPE) who satisfied the eligibility criteria and who were planned for surgery according to the guidelines of the American Urology Association were included in this prospective, randomized study.[2] Inclusion criteria: a] Age > 50 years, b] IPSS $>7$, c] Prostate volume (TRUS): $>20$ and $<80 \mathrm{cc}$, d] Q $\max <15$ $\mathrm{ml} / \mathrm{sec}$. Exclusion criteria: a] History of prostate, bladder or urethral surgery. b] History of spinal surgery or spinal trauma. c] Neurological disease. d] PVRU>300cc.
Initial evaluation included a detailed clinical history including the International Prostate Symptom Score (IPSS), quality of life (QOL) score, physical examination including digital rectal and focused neurological examination, urinalysis, serum prostate specific antigen (PSA) measurement, prostate volume estimation by transrectal ultrasound (TRUS), postvoid residual urine (PVRU) measurement by abdominal ultrasound and Qmax measurement on uroflowmetry. Eligible patients were randomized to one of two groups. Group A: underwent PVP using the 100W KTP laser. Group B underwent standard TURP. Randomization was done in a 1:1 ratio using a sealed envelope sequence.

\section{Surgical Procedure}

All procedures were performed by one of the two consultant urologists in department, each of whom were skilled in TURP and KTP-PVP.

\section{Group A}

For PVP, a continuous flow 23F laserscope was used. The lens employed was a 30-degree lens and the irrigant used was $0.9 \%$ normal saline. The fiber was a 600 micron, 70 degree side firing laser fiber emitting green light at 532 nm. At first, median lobe was lased and thereafter the lateral lobes were lased in a symmetrical manner. Anterior vaporization if needed was then performed. Tissue was vaporized down to the prostatic capsule until an unobstructed view of the trigone and a TURP like fossa was obtained. Vaporization was achieved by moving the laser fiber slowly and constantly in a "paint brush fashion" taking care to keep the fiber in "near contact" with the prostatic tissue. If any bleeding vessels were encountered 


\section{International Journal of Science and Research (IJSR) \\ ISSN (Online): 2319-7064}

Index Copernicus Value (2013): 6.14 | Impact Factor (2015): 6.391

during vaporization, coagulation was accomplished by defocusing the laser fiber (increasing working distance to 3-4 $\mathrm{mm}$ ) or by reducing the power setting to $40 \mathrm{~W}$ from $100 \mathrm{~W}$.

\section{Group B}

TURP was done using a 26F continuous flow resectoscope. The lens employed was a 30-degree lens and the irrigant used was $1.5 \%$ Glycine. A standard tungsten cutting wire loop at a setting of $150 \mathrm{~W}$ cutting and $80 \mathrm{~W}$ coagulation was used. The resection was carried down to the surgical capsule from bladder neck up to the verumontanum. An indwelling $22 \mathrm{~F}$ three-way Foley's catheter was inserted into the bladder. Irrigation with $0.9 \%$ normal saline was started postoperatively if deemed necessary until the urine was sufficiently clear. Catheter was removed $24 \mathrm{~h}$ after the irrigation is stopped and the urine is sufficiently clear. Patients who failed trial without catheter were recatheterized and a voiding trial was given again after 5 days. All patients received an intravenous antibiotic at induction and an oral antibiotic was continued till five days post catheter removal. Intraoperative and postoperative parameters recorded included the operative time, amount of irrigation fluid used intraoperatively, whether postoperative irrigation was instituted, duration of postoperative irrigation, duration of catheterization and postoperative hemoglobin concentration. All patients were followed up at 1, 3and 6 months. At each follow-up visit, IPSS, QOL, Qmax, PVRU, residual prostate volume and complications, if any were recorded.

\section{Statistical Analysis}

The parametric outcomes were expressed as the mean \pm SD of the group. The two-tailed Student t-test was used as a statistical tool to see the significance level. Categorical data in perioperative or complications outcome were analyzed by the nonparametric Mann-Whitney "U" test, chi-square and Fisher's exact tests. $P$ values $<0.05$ were considered statistically significant.

\section{Results}

Out of 167 patients screened, 126 were found eligible and were randomized, 63 each to Group A and B respectively , of which one and four patients in Group A and B respectively were subsequently excluded leaving 62 and 59 patients in Group A and B respectively available for analysis. The baseline characteristics of the two groups including mean age, IPSS score, QOL score, prostate volume, serum PSA, Qmax, PVRU, and preoperative hemoglobin were similar with no significant differences [Table 1]. In both groups, there was significant improvement in the IPSS score, QOL score, prostate volume, Qmax and PVRU, as compared to the baseline at each of the follow-up visits with the most dramatic improvement being seen at the first month follow-up.

Overall IPSS score decreased by $72.16 \%$ and $70.31 \%$, prostate volume decreased by $43.32 \%$ and $47.95 \%$, Qmax increased by $161.54 \%$ and $172.86 \%$, PVRU decreased by $84.53 \%$ and $83.76 \%$ at 6 months in Group A and B, respectively. Between the two groups, there was no significant difference in the IPSS score, QOL score, prostate volume, Qmax and PVRU at each of the followup visits. Data pertaining to the perioperative period is summarized in Table 2. Operative time was significantly longer in Group A when compared to Group B. The need, amount and duration of postoperative irrigation along with duration of postoperative catheterization were all significantly lesser in Group A as compared to Group B. The postoperative hemoglobin percentage was significantly higher in Group A as compared to Group B. The complications in each of the two groups are summarized in Table 3. Although the overall complication rate did not differ significantly between the two groups, the rate of clot retention and that of blood transfusion was significantly higher in Group B when compared to Group A. Dysuria in the early postoperative period was more common in Group A as compared to Group B, Phenazopyridine was prescribed when dysuria was not related to a positive urine culture.

Table 1: Baseline Characteristics

\begin{tabular}{|c|c|c|c|}
\hline & $\begin{array}{c}\text { Group } \\
\mathrm{A}(\mathrm{PVP}=62)\end{array}$ & $\begin{array}{c}\text { Group } \\
\text { B(TURP=59) }\end{array}$ & P value \\
\hline Age(years) & $65.72 \pm 7.41$ & $64.38 \pm 8.01$ & 0.562 \\
\hline $\mathrm{Hb}(\mathrm{gm} / \mathrm{dl})$ & $13.18 \pm 1.21$ & $12.81 \pm 1.32$ & 0.221 \\
\hline IPSS Score & $19.02 \pm 3.21$ & $20.18 \pm 3.78$ & 0.183 \\
\hline QOL Score & $3.67 \pm 0.78$ & $3.78 \pm 0.61$ & 0.231 \\
\hline $\begin{array}{c}\text { Prostate } \\
\text { volume(ml) }\end{array}$ & $43.67 \pm 13.68$ & $48.78 \pm 14.72$ & 0.131 \\
\hline \begin{tabular}{c} 
Se.PSA(ng/ml) \\
\hline Q-max (ml/min)
\end{tabular} & $2.13 \pm 1.56$ & $2.68 \pm 1.67$ & 0.362 \\
\hline PVR(ml) & $144.78 \pm 68.34$ & $140.6 \pm 64.78$ & 0.742 \\
\hline
\end{tabular}

Table 2: Perioperative data

\begin{tabular}{|l|c|c|c|}
\hline & $\begin{array}{c}\text { Group } \\
\mathrm{A}(\mathrm{PVP}=62)\end{array}$ & $\begin{array}{c}\text { Group } \\
\mathrm{B}(\mathrm{TURP}=59)\end{array}$ & P value \\
\hline $\begin{array}{l}\text { Operative } \\
\text { Time(min) }\end{array}$ & $\begin{array}{c}52.17 \pm \\
10.13\end{array}$ & $41.72 \pm 11.93$ & $<0.001$ \\
\hline $\begin{array}{l}\text { Amount of } \\
\text { irrigation fluid used } \\
\text { intraoperative (L) }\end{array}$ & $16.31 \pm 4.20$ & $18.91 \pm 5.2$ & 0.062 \\
\hline $\begin{array}{l}\text { Postoperative } \\
\text { irrigation }\end{array}$ & $3(4.84 \%)$ & $35(59.32 \%)$ & $<0.001$ \\
\hline $\begin{array}{l}\text { Duration of } \\
\text { irrigation(Hrs) }\end{array}$ & $0.36 \pm 1.78$ & $22.68 \pm 13.20$ & $<0.001$ \\
\hline $\begin{array}{l}\text { Duration of } \\
\text { catheterization(Hrs) }\end{array}$ & $23.45 \pm 1.91$ & $48.32 \pm 14.61$ & $<0.001$ \\
\hline $\begin{array}{l}\text { Postoperative } \\
\text { hemoglobin\% } \\
\text { (g/dl) }\end{array}$ & $12.45 \pm 1.12$ & $11.12 \pm 1.23$ & $<0.001$ \\
\hline
\end{tabular}




\section{International Journal of Science and Research (IJSR) ISSN (Online): 2319-7064}

Index Copernicus Value (2013): 6.14 | Impact Factor (2015): 6.391

Table 3: Complications

\begin{tabular}{|c|c|c|c|}
\hline & $\begin{array}{c}\text { Group } \\
\text { A(PVP=62) }\end{array}$ & $\begin{array}{c}\text { Group } \\
\text { B(TURP=59) }\end{array}$ & P value \\
\hline Dysuria & $14(22.58 \%)$ & $8(13.56 \%)$ & 0.036 \\
\hline Clot retention & 0 & $7(11.86 \%)$ & 0.013 \\
\hline $\begin{array}{c}\text { Blood } \\
\text { transfusion }\end{array}$ & 0 & $6(10.07 \%)$ & 0.021 \\
\hline UTI & $6(9.68 \%)$ & $7(11.86 \%)$ & 0.856 \\
\hline $\begin{array}{c}\text { Urethral } \\
\text { stricture }\end{array}$ & $2(3.23 \%)$ & $3(5.08 \%)$ & 0.642 \\
\hline $\begin{array}{c}\text { Bladder neck } \\
\text { contracture }\end{array}$ & $2(3.23 \%)$ & $2(3.39 \%)$ & 1.000 \\
\hline \begin{tabular}{c} 
TUR Syndrome \\
\hline
\end{tabular} & 0 & $2(3.39 \%)$ & 0.487 \\
\hline
\end{tabular}

\section{Discussion}

The first clinical experience with pure KTP-PVP was reported by Malek in 1998 who used a 60W laser.[3] Subsequently, the $80 \mathrm{~W}$ and $100 \mathrm{~W}$ KTP laser were introduced. Various authors with follow-up ranging from one to five years have reported favorably on the efficacy and safety profile of KTP-PVP.[4-11] Further, favorable outcomes have been reported for KTP-PVP even in highrisk patients and in those with larger glands.[12-15] The first prospective though nonrandomized comparison between KTP-PVP and TURP with a six-month follow-up was reported by Bachmann et al. in 2005. They found that though the overall perioperative complication rates between the two groups were similar, patients undergoing PVP had significantly lesser drop in hemoglobin percentage and serum sodium postoperatively. Further, the PVP group had a significantly shorter catheter time and hospital stay. As far as improvement in IPSS, QOL, Qmax and PVRU was concerned, no significant difference was noted between the two groups at six months.[16] Intermediate term results with two-year follow-up of the above mentioned prospective non-randomized study were published in 2008. The authors reported that the rates of intraoperative bleeding, blood transfusion, capsular perforation and postoperative clot retention were significantly lower in patients in the PVP group whereas the incidence of urethral and bladder neck strictures did not differ significantly between the two groups. Catheterization time and hospital stay were significantly lesser in the PVP group. Though improvement in Qmax and decrease in prostate volume and PSA were significantly higher in the TURP group, improvement in IPSS and PVRU did not differ significantly between the two groups. The authors concluded that KTP-PVP was more favorable in terms of perioperative safety and had comparable functional outcomes.[17]

The authors, Bouchier-Hayes et al., having earlier published interim results in 2006, later published their final data.[ 18, 19] Of 119 patients randomized, 10 refused surgery leaving 50 and 59 patients who underwent TURP AND KTP-PVP respectively. Of these 39 and 46 patients in the TURP and KTP-PVP groups respectively, were available for analysis at 12 months. Both groups showed significant improvements in IPSS, QOL, Bother score, Qmax and PVRU at 12 months when compared to the baseline with no significant difference noted between them. Patients undergoing KTP-PVP had significantly shorter catheterization time (13 vs. $44.2 \mathrm{~h}$ ), shorter length of inpatient stay (1.09 vs. 3.6 days) and lesser blood loss. Further, complications were less frequent in the KTP-PVP group. In oue study at 6 months follow-up, efficacy of KTP-PVP is comparable to TURP with no significant differences noted. As far as safety is concerned, KTP-PVP was associated with significantly less blood loss, clot retention and transfusion rates. In our study, $22.58 \%$ of KTP-PVP patients complained of transient dysuria in the early postoperative period, a much higher rate than that reported in other KTP-PVP series.[16, 17, 19] Dysuria is primarily caused by coagulation rather than vaporization of the tissue and its severity correlates with the volume of coagulated tissue. Excessive coagulation may be related to operator factors and/or patient factors. A possible explanation of the higher rate of dysuria in our study could be the limited experience of the operators with PVP to begin with. One drawback of this study is that since patients with prostate volumes $>80 \mathrm{cc}$ were excluded, the results of this study cannot be extrapolated to BPE patients with larger prostates.

\section{Conclusions}

KTP-PVP is an equally efficacious alternative to TURP in the management of LUTS due to BPE with durable results and lesser complications. It has benefits of significantly lesser perioperative blood loss and transfusion requirements along with a shorter catheterization time, so it is a good alternative for high risk cardiac patients. More long term studies are needed to clearly define the place of KTP-PVP in the management of patients with BPE.

\section{References}

[1] Wosnitzer MS, Rutman MP. KTP/LBO Laser Vaporization of the Prostate. Urol Clin North Am 2009;36:471-83.

[2] AUA Practice Guidelines Committee. AUA guideline on management of benign prostatic hyperplasia (2003). Chapter 1: Diagnosis and treatment recommendations. J Urol 2003;170:530-47.

[3] Malek RS, Barrett DM, Kuntzman RS. High-power potassium-titanylphosphate (KTP/532) laser vaporization prostatectomy: 24 hours later. Urology 1998;51:254-6.

[4] Hai MA, Malek RS. Photoselective vaporization of the prostate: Initial experience with a new $80 \mathrm{~W}$ KTP laser for the treatment of benign prostatic hyperplasia. J Endourol 2003;17:93-6.

[5] Te AE, Malloy TR, Stein BS, Ulchaker JC, Nseyo UO, Hai MA, et al. Photoselective vaporization of the prostate for the treatment of benign prostatic hyperplasia: 12-month results from the first United States multicenter prospective trial. J Urol 2004;172:1404-8.

[6] Malek RS, Kuntzman RS, Barrett DM. Photoselective potassium-titanylphosphate laser vaporization of the 


\section{International Journal of Science and Research (IJSR) \\ ISSN (Online): 2319-7064}

Index Copernicus Value (2013): 6.14 | Impact Factor (2015): 6.391

benign obstructive prostate Observations on long-term outcomes. J Urol 2005;174:1344-8.

[7] Bachmann A, Ruszat R, Wyler S, Reich O, Seifert $\mathrm{HH}$, Muller A, et al. Photoselective vaporization of the prostate: The basel experience after 108 procedures. Eur Urol 2005;47:798-804.

[8] Sarica K, Alkan E, Luleci H, Taşci AI. Photoselective vaporization of the enlarged prostate with KTP laser: Long-term results in 240 patients. J Endourol 2005;19:1199-202.

[9] Seki N, Nomura H, Yamaguchi A, Naito S. Effects of photoselective vaporization of the prostate on urodynamics in patients with benign prostatic hyperplasia. J Urol 2008;180:1024-8.

[10] Hamann MF, Naumann CM, Seif C, Van der Horst C, Junemann KP, Braun PM. Functional outcome following photoselective vaporization of the prostate (PVP): Urodynamic findings within 12 months follow-up. Eur Urol 2008;54:902-7.

[11]Ruszat R, Seitz M, Wyler SF, Abe C, Rieken M, Reich O, et al. GreenLight laser vaporization of the prostate: Single-center experience and longterm results after 500 procedures. Eur Urol 2008;54:893901.

[12] Reich O, Bachmann A, Siebels M, Hofstetter A, Stief CG, Sulser T. High power $(80 \mathrm{~W})$ potassium-titanylphosphate laser vaporization of the prostate in 66 high risk patients. J Urol 2005;173:158-60.

[13]Fu WJ, Hong BF, Wang XX, Yang Y, Cai W, Gao JP, et al. Evaluation of GreenLight photoselective vaporization of the prostate for the treatment of highrisk patients with benign prostatic hyperplasia. Asian J Androl 2006;8:367-71.

[14] Ruszat R, Wyler S, Forster T, Reich O, Stief CG, Gasser TC, et al. Safety and effectiveness of photoselective vaporization of the prostate (PVP) in patients on ongoing oral anticoagulation. Eur Urol 2007;51:1031-8.

[15] Rajbabu K, Chandrasekara SK, Barber NJ, Walsh K, Muir GH. Photoselective vaporization of the prostate with the potassiumtitanyl- phosphate laser in men with prostates of $>100 \mathrm{~mL}$. BJU Int 2007;100:593-8.

[16] Bachmann A, Schurch L, Ruszat R, Wyler SF, Seifert $\mathrm{HH}$, Muller A, et al. Photoselective vaporization (PVP) versus transurethral resection of the prostate (TURP): A prospective bicentre study of perioperative morbidity and early functional outcome. Eur Urol 2005;48:965-71.

[17] Ruszat R, Wyler SF, Seitz M, Lehmann K, Abe C, Bonkat $\mathrm{G}$, et al. Comparison of potassium-titanylphosphate laser vaporization of the prostate and transurethral resection of the prostate: Update of a prospective non-randomized two-centre study. BJU Int 2008; 102:1432-8.

[18] Bouchier-Hayes DM, Anderson P, Van Appledorn S, Bugeja P, Costello AJ. KTP laser versus transurethral resection: Early results of a randomized trial. J Endourol 2006;20:580-5.

[19] Bouchier-Hayes DM, Van Appledorn S, Bugeja P, Crowe H, Challacombe B, Costello AJ. A randomized trial of photoselective vaporization of the prostate using the $80-\mathrm{W}$ potassium-titanylphosphate laser vs transurethral prostatectomy, with a 1-year follow-up. BJU Int 2010;105:964-9.

\section{Author Profile}

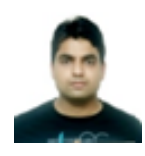

Harsh Gupta, MBBS, MS, MCh (Urology), Dr S N Medical College, Jodhpur (India)

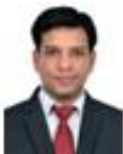

Suresh Goyal, MBBS, MS, MCh (Urology), Dr S N Medical College, Jodhpur (India)

Volume 5 Issue 6, June 2016 www.ijsr.net 